\title{
Comparison of the Effects of Acetaminophen Plus Ibuprofen to Treat Fever Than any of the Two Alone in Febrile Children
}

\author{
Noor Mohammad Noori, ${ }^{1}$ Ghasem Miri-Aliabad, ${ }^{1}$ Tahereh Boryri, ${ }^{2}$ Alireza Teimouri, ${ }^{1,}$ and Gholamreza \\ Soleimani ${ }^{1}$ \\ ${ }^{1}$ Children and Adolescent Health Research Center, Zahedan University of Medical Sciences, Zahedan, IR Iran \\ ${ }^{2}$ Department of Midwifery, Faculty of Nursing and Midwifery, Zahedan University of Medical Sciences, Zahedan, IR Iran \\ "Corresponding author: Alireza Teimouri, Faculty of Medicine, Children and Adolescent Health Research Center, Zahedan University of Medical Sciences, Zahedan, IR Iran. \\ E-mail: alirezateimouri260@gmail.com
}

Received 2014 April 23; Accepted 2014 October 12.

\begin{abstract}
Background: Fever is a natural response of the host to infection and a normal part of children's infectious disease.

Objectives: The purpose of the study was comparison of the combined treatment of acetaminophen and ibuprofen compact with each treatment alone.

Methods: This Double-blind clinical trial study was done on 540 children with $38^{\circ} \mathrm{C}$ to $41^{\circ} \mathrm{C}$ as body temperature. Eligible children after considering inclusion criteria divided in three groups randomly. First group of 183 patients administrated with acetaminophen, the second and the third groups of 178 and 179 patients with ibuprofen and combination. The first dose of antipyretic drug was administered to the patient under the supervision of a physician or nurse. After explanation of benefits and marginal effects to the parents if they accepted the conditions their children were admitted to the study. Parents were free if they wish to withdraw the study before completing. Information of each patient was recorded on a form. The data were analyzed by descriptive statistic, one-way ANOVA and SPSS software version 16.

Results: Out of sample 60.6\% were boy. The mean age of children treated with acetaminophen, ibuprofen and combination therapy was $2.21 \pm 2.49,3.00 \pm 2.92$ and $2.22 \pm 2.33$ years in the order given. The results showed statistical difference in two ( $F=4.45$ and $P$ $=0.012)$ and four hours $(\mathrm{F}=3.11$ and $\mathrm{P}=0.045)$ after taking drug. A significant difference not observed in the value of temperature decrease within 2 - 4 hours after drug intake, $(\mathrm{F}=2.49, \mathrm{P}=0.084)$ but in the time of 0-2 $(\mathrm{P}=0.012)$ and $4-6$ hours $(\mathrm{P}=0.001)$ was observed.

Conclusions: The findings of this study showed that acetaminophen is more effective for a short time but the combination in the long time when ibuprofen placed in the middle position with the respect of time.
\end{abstract}

Keywords: Fever, Acetaminophen, Ibuprofen, Combination, Impact

\section{Background}

Fever is a normal response of the host to infection and a normal part of childhood illnesses that annually affects 70 percent of preschool children [1]. Infants and young children are sensitive and susceptible to fever especially due to the small body size, having high body surface area to weight and lower subcutaneous fat. Although many experts consider fever as beneficial physiological response to the process of infection, but continuous fever can lead to irritability and agitation in children and anxiety in parents [2]. Physicians usually in addition of antipyretic drugs are used from non- pharmacologic and physical measures to reduce body temperature [3]. Pharmaceutical agents for the treatment of fever and associated symptoms are available without a prescription and widely used, but the best treatment is unknown [4].

Acetaminophen as an antipyretic drug is widely used because of high efficacy and safety [5]. This drug is a derivative of Para amino phenol in which inhibits the cyclooxygenase enzyme and prevents releasing and formation of prostaglandins [6]. Ibuprofen also is one of Propionic acid derivatives like acetaminophen which inhibits prostaglandin biosynthesis [2]. Paracetamol and ibuprofen are increasingly used to treat fever and the associated symptoms, although it is not known whether the combination of these drugs is better than using of either drug alone or not [7].

\section{Objectives}

The purpose of the study was a comparison of the effects of combined treatment of acetaminophen plus ibuprofen compared with effects of each one in febrile children aged six months to 10 years. 


\section{Methods}

This double-blind clinical trial study was done on referral children to the pediatric emergency department with $38^{\circ} \mathrm{C}$ to $41^{\circ} \mathrm{C}$ as body temperature due to febrile illness. Patients with a history of intolerance, allergy or contraindication to the use of these medications, need for hospitalization, dehydration, chronic lung disease (exception of asthma), cardiac diseases, neurologic, hepatic and renal diseases, and those children whose parents could not care them at home were excluded from the study. In order to fever control, the first group with acetaminophen $15 \mathrm{mg} / \mathrm{kg} / \mathrm{dose}$, the second group with ibuprofen $10 \mathrm{mg} / \mathrm{kg} /$ dose and the third group with a combination of acetaminophen plus ibuprofen were treated. From a total of 540 children who were eligible for inclusion to the study the first group was included of 183 patients, the second and the third groups were included of 178 and 179 patients, respectively. The first dose of antipyretic drug was administered to the patient under the supervision of a physician or nurse. Minimum interval between successive doses of acetaminophen and ibuprofen were 4 and 6 hours, respectively. The benefits and side effects of drugs and treatment and the nature of febrile illness were explained to the parents and if the parents accepted the conditions were admitted to the study. Adverse effects including of allergic reaction (pruritic rash), and hepatotoxicity following overdose which may in turn lead to organ degeneration and death. Other side effects due to acetaminophen administration would be asthma, rhino conjunctivitis, eczema and atopy. Gastrointestinal bleeding and renal failure are serious side effects for Ibuprofen. Both paracetamol and ibuprofen have been shown that have equal role in children safety for fever treatment.

Parents were free if they wish to withdraw the study before completing. Information on each patient were included of age, sex, weight, temperature, duration of fever, antibiotic use, use of acetaminophen or ibuprofen before referring, appetite, sleep, patient's activities, diagnosis, history of asthma and a history of seizure due to fever in the past were recorded in the patients data form. The prepared data were analyzed with SPSS software version 16 and descriptive statistics such as mean and standard deviation with one-way ANOVA were applied to show the results.

\section{Results}

Out of 540 children in the study 326 (60.6\%) were boy. The mean of age for boys and girls were $2.38 \pm 2.5$ and 2.6 \pm 2.78 years, respectively. The average of weight for boys and girls were $11.55 \pm 4.96$ and $11.93 \pm 5.77 \mathrm{~kg}$, respectively. The mean age of children treated with acetaminophen, ibuprofen and combination therapy was $2.21 \pm 2.49,3.00$ \pm 2.92 and $2.22 \pm 2.33$ years in the order given. The average of weight for children who treated with acetaminophen, ibuprofen and combination therapy was $11.35 \pm 5.23,12.79$ \pm 6.25 and $10.98 \pm 4.04 \mathrm{~kg}$, respectively. The average of temperature at the admission, 2, 4 and 6 hours after administration with acetaminophen, ibuprofen and combination therapy are shown in Table 1 . The average of temperature measured at 2 and 4 hours after drug intake in the three groups showed different significant while at admission and 6 hours after taking the drug non-significant differences were observed in the 3 groups. The average of temperature on admission, 2, 4 and 6 hours after drug intake in each group and was compared with each other. The results show that not significant different observed in the average of temperature in the admission and $6 \mathrm{~h}$ after taking drugs. But after 2 hours $(\mathrm{F}=4.45$ and $\mathrm{P}=0.012)$ and 4 hours $(\mathrm{F}=$ 3.11 and $\mathrm{P}=0.045$ ) of drug intake were observed significant differences in the intensity of the fever in all groups. Two hours after taking drug a significant difference between the mean of temperature for acetaminophen and combination therapy in favor of acetaminophen was observed. And 4 hours after taking drug a significant difference between the mean of temperature for ibuprofen and combination therapy in favor of ibuprofen was observed. In Table 2 the mean of decrease in temperature has been shown for the time of drug administration and 2, 4 and 6 hours after admission. According to the results there is no significant difference in the value of temperature decrease within 2 - 4 hours after drug intake between three groups, $(\mathrm{F}=2.49, \mathrm{P}=0.084)$. That means the amount of temperature decline within this time interval not affected by three different medications. In time interval of admission and 2 hours after using drug $(\mathrm{P}=0.012)$ and time interval after 4 and 6 hours after using drug (0.001). The results of Tukey test show that the difference in declined amount of temperature in the time between admission and the second hour is significant in favor of acetaminophen for the pair of combination and acetaminophen. Different in decreasing values of fever in time interval between 4 and 6 hours after administration is significant and is due to combination therapy, acetaminophen and combination therapy, and ibuprofen pairs. This difference in favor of combination therapy in reducing the temperature is high.

\section{Discussion}

Ibuprofen and acetaminophen are more available in the market and widely are used in respect of other fever and pain medications. The present study investigated the effectiveness of ibuprofen, acetaminophen and combination therapy in reducing the temperature and stopping 
Table 1. Average of Fever and the Declined Amounts for Acetaminophen, Ibuprofen and Combination Therapy

\begin{tabular}{|c|c|c|c|c|c|c|c|}
\hline \multirow[t]{2}{*}{ Time/Drug } & \multirow[t]{2}{*}{ Mean \pm SD of Temperature } & \multicolumn{2}{|c|}{ 95\%CI } & \multirow[t]{2}{*}{$\mathbf{F}$} & \multirow[t]{2}{*}{ P Value } & \multirow[t]{2}{*}{ Min } & \multirow[t]{2}{*}{ Max } \\
\hline & & Low & Up & & & & \\
\hline Admission time & & & & 0.26 & 0.77 & & \\
\hline Acetaminophen & $39.03 \pm 0.49$ & 38.96 & 39.1 & & & 38 & 40.2 \\
\hline Ibuprofen & $39.07 \pm 0.54$ & 38.99 & 39.15 & & & 38 & 40.5 \\
\hline Both & $39.04 \pm 0.52$ & 38.96 & 39.12 & & & 38 & 41 \\
\hline 2 hours after admission & & & & 4.45 & 0.012 & & \\
\hline Acetaminophen & $37.71 \pm 0.70$ & 37.61 & 37.81 & & & 36 & 40 \\
\hline Ibuprofen & $37.82 \pm 0.55$ & 37.74 & 37.9 & & & 36.5 & 39 \\
\hline Both & $37.91 \pm 0.71$ & 37.81 & 38.02 & & & 36.5 & 40 \\
\hline 4 hours after admission & & & & 3.11 & 0.045 & & \\
\hline Acetaminophen & $37.1 \pm 0.40$ & 37.04 & 37.16 & & & 36.2 & 39 \\
\hline Ibuprofen & $37.09 \pm 0.34$ & 37.04 & 37.14 & & & 36.1 & 38.3 \\
\hline Both & $37.19 \pm 0.50$ & 37.12 & 37.26 & & & 36 & 39 \\
\hline 6 hours after admission & & & & 1.05 & 0.351 & & \\
\hline Acetaminophen & $36.96 \pm 0.19$ & 36.94 & 36.99 & & & 36 & 38 \\
\hline Ibuprofen & $36.96 \pm 0.18$ & 36.93 & 36.98 & & & 36 & 37.8 \\
\hline Both & $36.94 \pm 0.19$ & 36.91 & 36.96 & & & 36 & 37.6 \\
\hline \multirow[t]{2}{*}{ Time Interval/Time } & Mean \pm SD of declined amounts & \multicolumn{2}{|c|}{ 95\%CI } & $\mathbf{F}$ & P Value & Min & Max \\
\hline & & Low & Up & & & & \\
\hline 2 Initial hours after admission & & & & 4.45 & 0.012 & & \\
\hline Acetaminophen & $1.32 \pm 0.72$ & 1.22 & 1.43 & & & -1.5 & 3 \\
\hline Ibuprofen & $1.25 \pm 0.50$ & 1.17 & 1.32 & & & -0.5 & 3.5 \\
\hline Both & $1.13 \pm 0.65$ & 1.03 & 1.22 & & & -1 & 2.7 \\
\hline Second 2 hours, time interval ( 2 - 4 ) after admission & & & & 2.49 & 0.084 & & \\
\hline Acetaminophen & $0.61 \pm 0.59$ & 0.53 & 0.7 & & & -1 & 2.5 \\
\hline Ibuprofen & $0.73 \pm 0.46$ & 0.66 & 0.8 & & & -0.5 & 1.8 \\
\hline Both & $0.72 \pm 0.64$ & 0.63 & 0.82 & & & -1.2 & 2.5 \\
\hline Third 2 hours, time interval ( 4 - 6) after admission & & & & 6.82 & 0.001 & & \\
\hline Acetaminophen & $0.13 \pm 0.32$ & 0.09 & 0.18 & & & -0.8 & 1.6 \\
\hline Ibuprofen & $0.14 \pm 0.27$ & 0.1 & 0.18 & & & -0.7 & 1.3 \\
\hline Both & $0.25 \pm 0.44$ & 0.19 & 0.32 & & & -0.8 & 2 \\
\hline
\end{tabular}

its continuity. The temperature values at the time of admission, 2, 4 and 6 hours after using and followed by measuring changes in temperature during the first, the second and the third 2 hours were compared. At admitted time, the average of temperatures in three medications showed no significant differences but The average of temperatures 2 hours after taking the medication of acetaminophen, ibuprofen and combination therapy were $37.71^{\circ} \mathrm{C}, 37.82^{\circ} \mathrm{C}$ and $37.91^{\circ} \mathrm{C}$, respectively in which showed significantly different. This difference was statistically significant due to the combination and acetaminophen in favor of acetaminophen. After four hours of taking the medications, the average of temperature for acetaminophen, ibuprofen and combination therapy were $37.10^{\circ} \mathrm{C}, 37.09^{\circ} \mathrm{C}$ and $37.19^{\circ} \mathrm{C}$, respectively in which was observed significant different in favor of ibuprofen in the paired of combination and ibuprofen. Six hours after administration, the average of temperature for the three groups has a slight dif- 
Table 2. Results due to Tukey Test

\begin{tabular}{|c|c|c|c|c|c|c|}
\hline \multirow[t]{2}{*}{ Time } & \multirow[t]{2}{*}{ Drug $\mathrm{i}$} & \multirow[t]{2}{*}{ Drug j } & \multirow[t]{2}{*}{ Mean of Drug $\mathbf{i}$-Drug $\mathbf{j}$} & \multirow[t]{2}{*}{ PValue } & \multicolumn{2}{|c|}{ 95\% CI } \\
\hline & & & & & Low & Up \\
\hline \multirow{5}{*}{ Two hours after admission } & \multirow{2}{*}{ Acetaminophen } & Ibuprofen & -0.11 & 0.230 & -0.27 & 0.05 \\
\hline & & Both & -0.2 & 0.010 & -0.37 & -0.04 \\
\hline & Ibuprofen & Acetaminophen & 0.11 & 0.230 & -0.05 & 0.27 \\
\hline & \multirow{2}{*}{ Both } & Acetaminophen & 0.2 & 0.010 & 0.04 & 0.37 \\
\hline & & Ibuprofen & 0.09 & 0.380 & -0.07 & 0.25 \\
\hline \multirow{5}{*}{ Four hours after admission } & \multirow{2}{*}{ Acetaminophen } & Ibuprofen & 0.01 & 0.990 & -0.1 & 0.11 \\
\hline & & Both & -0.09 & 0.090 & -0.2 & 0.01 \\
\hline & Ibuprofen & Acetaminophen & -0.01 & 0.990 & -0.11 & 0.1 \\
\hline & \multirow{2}{*}{ Both } & Acetaminophen & 0.09 & 0.090 & -0.01 & 0.2 \\
\hline & & Ibuprofen & 0.1 & 0.070 & -0.01 & 0.2 \\
\hline \multirow{6}{*}{2 initial hours after admission } & \multirow{2}{*}{ Acetaminophen } & Ibuprofen & 0.08 & 0.490 & -0.08 & 0.23 \\
\hline & & Both & 0.2 & 0.010 & 0.04 & 0.35 \\
\hline & \multirow{2}{*}{ Ibuprofen } & Acetaminophen & -0.08 & 0.490 & -0.23 & 0.08 \\
\hline & & Both & 0.12 & 0.170 & -0.04 & 0.28 \\
\hline & \multirow{2}{*}{ Both } & Acetaminophen & -0.2 & 0.010 & -0.35 & -0.04 \\
\hline & & Ibuprofen & -0.12 & 0.170 & -0.28 & 0.04 \\
\hline \multirow{5}{*}{$\begin{array}{l}\text { Third } 2 \text { hours, time interval ( } 4 \text { - } 6 \text { ) } \\
\text { after admission }\end{array}$} & \multirow{2}{*}{ Acetaminophen } & Ibuprofen & 0 & 1.000 & -0.09 & 0.08 \\
\hline & & Both & -0.12 & 0.000 & -0.21 & -0.03 \\
\hline & Ibuprofen & Both & -0.12 & 0.000 & -0.21 & -0.03 \\
\hline & \multirow{2}{*}{ Both } & Acetaminophen & 0.12 & 0.000 & 0.03 & 0.21 \\
\hline & & Ibuprofen & 0.12 & 0.000 & 0.03 & 0.21 \\
\hline
\end{tabular}

ference in favor of combination therapy but not significant. Sullivan and colleagues found in their study that taking acetaminophen and ibuprofen to treat fever is good and effective and impact of combined treatment is more effective than either alone when combination therapy likely associated with higher complication that is compatible with the results of the present study [8]. Hay AD and colleagues have suggested that medical care givers and parents better to use ibuprofen first to treat children with fever and should be advised to use ibuprofen plus paracetamol over either one with more consideration accordance with the relative risks and benefits [9]. In the present study, ibuprofen had more impact to reduced temperatures at four hours after taking medicine. In another study less evidence was observed for the efficacy of combination therapy in compared to acetaminophen and ibuprofen alone in which were consistent with our results after six hours of taking medicine [10]. In a study by Hollinghurst treatment with acetaminophen plus ibuprofen in reducing the temperature was more effective than both alone in which likely increase the risk of toxicity [11]. In another study also noted that there is still not enough evidence to support the guarantee of combined paracetamol and ibuprofen therapy and either alone [12]. In a meta-analysis by Southey et al. in 2009 showed that there wasn't a disparity in the treatment of fever by acetaminophen, ibuprofen and placebo. The study also showed that ibuprofen, paracetamol and placebo were equally effective, especially in the incidence of gastrointestinal symptoms, tolerance asthma and renal problems were similar [13]. Paul showed that co-treatment of ibuprofen plus acetaminophen had greater antipyretic efficacy related two drugs alone in 4 
hours in children. They also proposed that further prospective studies are needed to confirm the suitability of the antipyretic treatment regimen [14]. Hoover expressed that nearly a third of children have a fever during a visit to a physician and requires treatment to decrease fever. Also was noted that the combined treatment of acetaminophen plus ibuprofen were often used to reduce temperature in children [15]. Many Studies have shown that the temperature variation after the treatment of patients with combined therapy of ibuprofen and acetaminophen have similar impact in compare to each of them alone.

Sarrell and colleagues in their study indicated that an alternative treatment of acetaminophen $(12.5 \mathrm{mg} / \mathrm{kg})$ plus ibuprofen $(5 \mathrm{mg} / \mathrm{kg})$ every 4 hours for 3 days regardless of the initial dose was more effective than mono-therapy in infants and children [2]. The results of Perrott study showed that a single dose of acetaminophen has similar effects on pain control in compared to ibuprofen but ibuprofen with dose 5 to $10 \mathrm{mg}$ per $\mathrm{kg}$ has more antipyretic effect in compared to acetaminophen in 2, 4, 6 after treatment [16]. This was also shown in a meta-analysis that there is no systematic information that paracetamol is effective in treating fever and this preference was observed in compared to placebo [17]. In study by Kokki the effect of antipyretic paracetamol, ibuprofen and ketoprofen were compared with each other to reduce the child's temperature and showed that ketoprofen in the symptomatic treatment of fever in children is more effective than other drugs [18]. Wong concluded that the combination therapy compared to alternative antipyretic was more effective in reducing the temperature [19]. In a study by Smith observed that, despite of acetaminophen and ibuprofen alternative therapies for the treatment of pain in children, there is no evidence of the appropriateness and effectiveness of treatment. Studies in febrile children showed that adverse effects no increased because of short-term follow-up treatment. For this reason suggested that in short-term treatment with a regimen of acetaminophen plus ibuprofen in the treatment of pain that do not respond to monotherapy can be considered [20].

According to initial reduction of temperature in the first 2 hours and the third 2 hours after taking the drug the significant differences were observed. In the first 2 hours the temperature was declined at a rate of 1.32 , 1.25 and 1.13 centigrade degree, after administration of acetaminophen, ibuprofen and combination therapy respectively. This decrease was statistically significant and occurred in the paired of acetaminophen and combination therapy groups.

The mean of decreasing amounts in temperature indicated that for the first 2 hours acetaminophen is more beneficial than ibuprofen and combination therapy and is pre- ferred. in the second 2 hours between 2 and 4 hours after taking drugs not observed any statistical difference in the average of declining temperature but in the third 2 hours belong to time interval of 4 and 6 hours after drugs administration, the average of temperature decreases at a rate of $0.13,0.14$ and 0.25 were for acetaminophen, ibuprofen and combination therapy respectively and showed significant differences.

These differences suggest that combination therapy compared with each alone was preferred. Paracetamol could be the first choice of the antipyretic agents because of its safety for long term used. Rectal administration is useful for children with vomiting and intravenous administration is useful if rapid entry into the central nervous system and is without side effect with appropriate dose and its hepatotoxicity has been described in only a few individual as case reports. It would be suicidal and can be fatal if taken whether accidental or deliberate. Ibuprofen main effect establishes within three to four hours slightly longer than paracetamol. There is no evidence indicating any superiority of ibuprofen over paracetamol. As for its side effects reported low cases of gastritis, gastroduodenal ulcers and nephrotoxicity [21]. Recommend that only monotherapy for febrile children, in order to avoid potential side effects from multiple medication administration but Wong do not suggest any serious short term side effects from either alternating or combined antipyretic therapy $[19,22]$. In our study, we found that single dose of acetaminophen was preferable compared with ibuprofen and combination in the first two hours. We resulted similar to Wong study that did not suggest any side effects in short term for all types of treatments in children with fever.

The findings of this study showed that acetaminophen is more effective in compared to ibuprofen and combined therapy in the first 2 hours after drug administration but for the next 4 hours ibuprofen is more preferable. The results also showed that the combination of acetaminophen and ibuprofen in the long-term impact is more effective but with no significant side effects.

\section{Acknowledgments}

The study was approved by the ethics committee of the university as a research project (NO:2567), and written informed consent were obtained from all patients' parents. Therefore, all the authors would like to thank children's parents for their warm participants.

\section{Footnotes}

Authors' Contribution: All authors had equal role in design, statistical analysis and manuscript writing. 
Funding/Support: This paper had been done as a project supported by the children and Adolescent health research center, Zahedan University of Medical Sciences, Zahedan, Iran.

\section{References}

1. Hay AD, Costelloe C, Redmond NM, Montgomery AA, Fletcher M, Hollinghurst $S$, et al. Paracetamol plus ibuprofen for the treatment of fever in children (PITCH): randomised controlled trial. BMJ. 2008;337:1302. doi: 10.1136/bmj.a1302. [PubMed: 18765450].

2. Sarrell EM, Wielunsky E, Cohen HA. Antipyretic treatment in young children with fever: acetaminophen, ibuprofen, or both alternating in a randomized, double-blind study. Arch Pediatr Adolesc Med. 2006;160(2):197-202. doi: 10.1001/archpedi.160.2.197. [PubMed: 16461878].

3. Baraff LJ, Bass JW, Fleisher GR, Klein JO, McCracken GH, Powell KR, et al. Practice guideline for the management of infants and children 0 to 36 months of age with fever without source. Agency for Health Care Policy and Research. Ann Emerg Med. 1993;22(7):1198-210. [PubMed: 8517575].

4. Hollinghurst S, Redmond N, Costelloe C. Paracetamol, plus ibuprofen for the treatment of fever in children: economic evaluation of a randomized controlled trial. BMJ. 2008;337:1490.

5. Vauzelle-Kervroëdan F, d'Athis P, Pariente-Khayat A, Debregeas S, Olive G, Pons G, et al. Equivalent antipyretic activity of ibuprofen and paracetamol in febrile children. J Pediatr. 1997;131(5):683-7.

6. Brown RD, Kearns GL, Wilson JT. Integrated pharmacokineticpharmacodynamic model for acetaminophen, ibuprofen, and placebo antipyresis in children. $J$ Pharmacokinet Biopharm. 1998;26(5):559-79. [PubMed: 10205771].

7. Nouri NM, Rajaei S, Boriri T. Antipyretic efficacy of acetaminophen and ibuprofen in children aged 6 months to 10 years. Med J Hormozgan Univ. 2008;12:1-6.

8. Sullivan JE, Farrar HC. Fever and antipyretic use in children. Pediatrics. 2011;127(3):580-7. doi: 10.1542/peds.2010-3852. [PubMed: 21357332].

9. Hay AD, Redmond NM, Costelloe C, Montgomery AA, Fletcher M, Hollinghurst S, et al. Paracetamol and ibuprofen for the treatment of fever in children: the PITCH randomised controlled trial. Health Technol Assess. 2009;13(27):1-163. doi: 10.3310/hta13270. [PubMed: 19454182].

10. Purssell E. Systematic review of studies comparing combined treatment with paracetamol and ibuprofen, with either drug alone. Arch
Dis Child. 2011;96(12):1175-9. doi: 10.1136/archdischild-2011-300424. [PubMed: 21868405].

11. Hollinghurst S, Redmond N, Costelloe C, Montgomery A, Fletcher M, Peters TJ, et al. Paracetamol plus ibuprofen for the treatment of fever in children (PITCH): economic evaluation of a randomized controlled trial. BMJ. 2008;337(1490:):1-8. doi: 10.1136/bmj.a1490..

12. Keen J. Antipyretic drugs for children. BMJ. 2006;333(7557):4-5.

13. Southey ER, Soares-Weiser K, Kleijnen J. Systematic review and metaanalysis of the clinical safety and tolerability of ibuprofen compared with paracetamol in paediatric pain and fever. Curr Med Res Opin. 2009;25(9):2207-22. doi: 10.1185/03007990903116255. [PubMed: 19606950].

14. Paul IM, Sturgis SA, Yang C, Engle L, Watts H, Berlin CM. Efficacy of standard doses of Ibuprofen alone, alternating, and combined with acetaminophen for the treatment of febrile children. Clin Ther. 2010;32(14):2433-40. doi: 10.1016/j.clinthera.2011.01.006. [PubMed: 21353111].

15. Hoover L. AAP reports on the use of antipyretics for fever in children. Am Fam Physician. 2012;85(5):518-9. [PubMed: 22534232].

16. Perrott DA, Piira T, Goodenough B, Champion GD. Efficacy and safety of acetaminophen vs ibuprofen for treating children's pain or fever: a meta-analysis. Arch Pediatr Adolesc Med. 2004;158(6):521-6. doi: 10.1001/archpedi.158.6.521. [PubMed: 15184213].

17. Meremikwu MM, Oyo-Ita A. Paracetamol versus placebo or physical methods for treating fever in children. Cochrane Library. 2002 doi: 10.1002/14651858.CD003676.

18. Kokki H, Kokki M. Ketoprofen versus paracetamol (acetaminophen) or ibuprofen in the management of fever: results of two randomized, double-blind, double-dummy, parallel-group, repeated-dose, multicentre, phase III studies in children. Clin Drug Investig. 2010;30(6):37586. doi: 10.2165/11534930-000000000-00000. [PubMed: 20380479].

19. Wong T, Stang AS, Ganshorn H, Hartling L, Maconochie IK, Thomsen AM, et al. Combined and alternating paracetamol and ibuprofen therapy for febrile children. Evid Based Child Health A Cochrane Rev J. 2014;9(3):675-729.

20. Smith C, Goldman RD. Alternating acetaminophen and ibuprofen for pain in children. Can Fam Physician. 2012;58(6):645-7. [PubMed: 22700733].

21. Niehues T. The febrile child: diagnosis and treatment. Dtsch Arztebl Int. 2013;110(45):764-73. doi: 10.3238/arztebl.2013.0764. [PubMed: 24290365].

22. Wong T, Johnson DW, Ganshorn H, Maconochie IK, Hartling L, Stang AS. Combined and alternating paracetamol and ibuprofen therapy for fever in children. Cochrane Library. 2012. 